University of Nebraska - Lincoln

DigitalCommons@University of Nebraska - Lincoln

Sociology Department, Faculty Publications

Sociology, Department of

1993

\title{
The Contexts of Housework and the Paid Labor Force: Women's Perceptions of the Demand Levels of Their Work
}

\author{
Sheryl J. Grana \\ University of Minnesota, Duluth \\ Helen A. Moore \\ University of Nebraska-Lincoln, hmoore1@unl.edu \\ Janet K. Wilson \\ University of Arkansas at Little Rock, jwilson@uca.edu \\ Michelle Miller \\ Lincoln, Nebraska
}

Follow this and additional works at: https://digitalcommons.unl.edu/sociologyfacpub

Part of the Sociology Commons

Grana, Sheryl J.; Moore, Helen A.; Wilson, Janet K.; and Miller, Michelle, "The Contexts of Housework and the Paid Labor Force: Women's Perceptions of the Demand Levels of Their Work" (1993). Sociology Department, Faculty Publications. 98.

https://digitalcommons.unl.edu/sociologyfacpub/98

This Article is brought to you for free and open access by the Sociology, Department of at DigitalCommons@University of Nebraska - Lincoln. It has been accepted for inclusion in Sociology Department, Faculty Publications by an authorized administrator of DigitalCommons@University of Nebraska - Lincoln. 


\title{
The Contexts of Housework and the Paid Labor Force: Women's Perceptions of the Demand Levels of Their Work
}

\author{
Sheryl J. Grana \\ University of Minnesota, Duluth \\ Helen A. Moore \\ University of Nebraska-Lincoln \\ Janet K. Wilson \\ University of Arkansas at Little Rock \\ Michelle Miller
Lincoln, Nebraska
}

This research explores the work perceptions, both physical and mental, of women. The research finds that women's perceptions of waged and nonwaged labor differ greatly depending on the work environment. Perceptions of physical demands of waged labor are almost solely dependent on the type of paid labor women engage in. For homeworkers, perceptions of physical labor are influenced primarily by the number of hours invested in housework. The mental demands of waged and nonwaged labor are also perceived differently. Women in the waged economy report significantly higher mental demands than do homeworkers. This too varies across labor segments. The closest parallel between physical and mental demand perceptions is between homeworkers and women in the service sector of the waged economy. Overall the assumption that women perceive their work roles in the waged market and the home market similarly is negated. 
While women have always worked, the nature of their work has changed over time and place. That is, the context of the work women do, and where they do that work, results in differing perceptions of the meaning of "women's work." In this paper we examine women workers' perceptions of the physical and mental demands of their work in various sectors of the labor force and in the home. We are especially interested in the economic, social, and family factors that influence those perceptions and how these might vary across different work settings.

\section{Context of Paid Labor}

Women's work, traditionally, has been centered in the home. Historically, her job was to keep house, raise the children, and prior to the industrial revolution, assist in the farming chores. Later much of this labor was replaced by the growing commodities of the consumer market (Rosenfeld, 1985). By the turn of the 19th century, women were leaving their home workplace and entering the wage job market, working (mainly) in textile factories (Simmons, Freedmann, Ounkle, \& Blau, 1975, p. 43; Reskin \& Roos, 1990). Entry into factory work offered women 14- and 16hour work days, dangerous working conditions, and the tedious chore of keeping up with a machine (Wertheimer, 1977). A steady increase in female labor force participation from 1800 to 1940 was followed by a drastic leap in rates during the war years.

Even as social pressures in the late 1940s pushed for women to return to the home (Deckard, 1983), many remained in the work force and the emerging service sector became their primary niche (Reskin \& Roos, 1990). The job context in these service sectors, especially clerical labor, centered around highly routinized tasks such as typing, filing, and time management (Kanter, 1977; Davies, 1982). This context for women's labor continues in today's workplace with females comprising $98 \%$ of all secretaries and $86 \%$ of all clerical workers (1990 Statistical Abstracts of the United States). In the four decades of the post-World War II labor market, women wage workers have come to closely resemble the total female population in demographics: age, educational attainment, racial composition, marital and family status (Reskin \& Roos, 1990).

\section{Context of Housework}

For many women, the primary arena of work remains within the home. How do these women differ in terms of their work and their per- 
ceptions of their work? Housework is not yet allocated a "wage" and is accorded a more negative social reputation because it is assumed to be less useful (Oakley, 1980).

Women participating in this unpaid home labor are labeled as not "real" workers (Daniels, 1987, p. 220). This may partially account for the general lack of research on women's participation in housework. When housework is considered a form of work, it is differentially treated by re- search which labels work as "either for the household or in the workplace" (Glazer, 1987, p. 238).

Some assume that with increased technology household tasks are "physically easier, take less time, require fewer specialized skills and can more easily be divided and accommodated to other activities" (Devault, 1987, p. 178). Robinson (1980, p. 64) argues, however, that "the mere presence of the machines makes little difference in the housework time." Indeed, it is wrong to conclude that the concept of "housework" is a thing of the past. As Robinson points out, machines are not labor saving but labor changing.

Thus, in a study of the value of home labor over a decade ago, one national insurance company valued women's work in the home at $\$ 18,000$ (Porter, 1978). Their analysis was based on an average work week of more than 90 hours for women with children working in the home. The annual salary figure was well above the average of most full-time employed women at that time period (\$11,051 in 1980) and remains so today. Berk (1988) argues that regardless of these "market cost" approaches, household labor remains socially necessary, irreplaceable as work, and undervalued in its contributions.

\section{Comparing Labor Force and Housework Contexts}

Aside from the issue of wages, housework and paid labor force employment are comparable in many ways. Glazer-Malbin and Waehrer (1976) identified both housework and paid labor force activities as "productive" labor. Schooler, Miller, Miller, and Richtand (1984) have recognized similarities across the two working conditions as well. They argue that in both spheres, the bottom line is that work must be done and that workers must be self-directed in their work. Several other dimensions are emphasized by Schooler et al., including the complexity of the work (certain chores in both contexts are complex), the degree of routinization (as well, certain chores are also routinized and monotonous), time pressures, the heaviness of physical labor (when applicable), dirtiness (when applicable), and the frequency of being held responsible for things out of one's control. 
Despite these work dimensions, much of women's work in both contexts continues to be devalued:

In relation to male labor, female labor is characterized as unproductive, marginal, trivial, temporary, intermittent, dispensable, less valuable, less skilled, and less physically demanding. These stereotypes apply both to female household labor and to women's labor in paid occupations. (Oakley, 1980, p. 8)

Hartmann (1981) compares both housework and paid labor force activities to dimensions of conflict and power relations in society. She argues that men exercise considerable power over women's labor in the home through the patriarchal structure of the family, while men maintain control over women in the labor market through their dominance of administrative and supervisory positions. This dual system segregates and devalues the work that women do in society, and increases the relative burdens for women working in and outside of the home.

Few studies focus on contrasting the demands and perceptions of women's work in these two different contexts. Specifically, little research has been conducted on women's perceptions of the physical and mental demands of the work they do. What influences a houseworker's perceptions of her housework as physically demanding? As mentally demanding? How does this contrast to the perceptions of women in the paid labor force? Are the work loads perceived as similar or different in the home and the paid labor force? Further, what motivates women, either in the home or paid labor force, to do this work when it is difficult? Does the effort come from the demands of the work itself, from others, or from internal motivations? The artificial dichotomy of labor for women can be dismantled to examine these work contexts.

\section{Factors Related to Work Demands}

In this paper, we consider women's perceptions of the mental and physical demands of their labor, comparing women in household and labor force activity. Past research on female laborers' descriptions of their work has focused on the amount of time spent in housework and in the paid labor force (Hartmann, 1981; Rexroat \& Shehan, 1987; Juster \& Stafford, 1985), the impact of multiple social roles on physical and psychological health (Pietromonacot, Manis, \& Frohardt-Laner, 1986; Coleman, Antonucci, Adelman, \& Crohan, 1987), and perceptions of strain or stress at work (Agassi, 1982). These variables may differentially affect perceptions of the demands of work for women at home or in the paid labor force. 


\section{Children}

The number of children in the household affects the reported job demands for both housewives and those in the paid labor force (Hartmann, 1981). This effect may be compounded for full-time homemakers who are likely to have more children, and younger children, than women who work outside the home (Stokes \& Peyton, 1986). More recently, women in the labor force and women working in the home have narrowed the gap in their family structure, especially for children under school age (Reskin \& Roos, 1990).

England and Farkas (1986) highlight the "emotional labor" of child care. For women in the paid labor force, extra effort is exerted to find capable guardianship for the child while the parent works. Problems arise when the child becomes ill or if the mother works variable shifts. Because the division of housework and child care still falls heavily on women, their work outside the home is compounded by additional work inside the home - the "double shift." We hypothesize, then, that the presence of preschoolers for both houseworkers and women in the paid labor market leads to an increase in perceived mental and physical demands of their particular jobs.

\section{Education}

Past research finds that the higher the level of schooling for a woman or her spouse, "the fewer the number of household tasks undertaken by the household as a whole, and the less time that households devote to them" (Berk, 1985, p. 94). Increased education may also reflect increases in household economic resources, including opportunities to hire others to accomplish cleaning, cooking, and child care tasks, changing the context of being a homeworker. Thus, as education increases for the houseworker, we might expect to find the physical and mental demands of housework to decrease because she chooses to invest less time in household chores.

In the paid labor force, higher education levels can lead to careers requiring high levels of cognitive investment (Parelius \& Parelius, 1978). Thus, we hypothesize that higher levels of education for women in the paid labor force will lead to higher levels of perceived mental job demands. Given the "semiprofessional" nature of much of women's professional work (nursing and teaching especially), the physical demands of women's labor may be high in these jobs as well. 


\section{Urban/Rural Settings}

The rural or urban setting of women's work also has an influence on job contexts. Rural women may be more highly involved in manual farm labor and intensive household commodity production, all of which is often categorized under "housework" by women respondents (Rosenfeld, 1985). The size of the town in which one lives also influences the range of paid jobs available, and the resulting demands from different jobs. As women move away from rural areas and into the cities, the amount of physical investment required for the job may shift, e.g., a shift from the manual farm tasks to the routinized tasks of service and clerical positions. More resources may be available in urban settings to ease the physical demands of housework, as well, with access to maid services, local laundries, child care facilities, and fast food restaurants.

We hypothesize that the perceived physical demands of work for both houseworkers and women in the paid labor force will be less in urban settings. As a result of increased employment in a wider range of jobs, which may more fully utilize women's abilities, the mental demands of work might then be greater for paid labor force participants living in an urban area. Because of urban conveniences and the lack of intensive rural farm tasks, the mental demands reported by urban houseworkers may be less than all other groups.

\section{Mental and Physical Health Status}

Important to past research on women and work is the woman's physical and mental health status. Several studies report that houseworkers as a group are more likely to be depressed than labor force participants (Haw, 1982). However, Shehan (1984) found no support for the hypothesis that paid labor force participants have better psychological health than houseworkers. Attempts to untangle these contradictory findings focus on a range of factors in the household that might influence health status. The number of children in the household (Pearlin, 1975), family income (Shehan, Burg, \& Rexroat, 1986, Shehan, 1984), social integration (Pearlin, 1975), and satisfaction with the housework role (Pearlin, 1975; Shehan et al., 1986) each influence the mental health status of houseworkers.

Haw (1982) argues that paid labor activity itself is a significant source of stress among women that may create mental and physical health problems. Haw attributes this negative outcome to the additional work of women's home responsibilities. Haynes and Feinleib (1980) found that women clerical workers with three or more children were more likely 
to develop coronary heart disease than labor force participants without children (11\%-6.5\%, respectively). They were also more likely to develop coronary heart disease when compared to houseworkers with the same number of children.

Liff (1981) found that "most" of the women factory workers she sampled preferred going to their paid job rather than staying home; only one-third said they would prefer to be a full-time houseworker. She did find a tendency toward poor mental health among these labor force participants, particularly among those women employed full time. These women were more likely to be depressed than part-time workers. Liff notes, however, that this depression came about because these workers had negative feelings about their job.

Shehan (1984) found that paid labor force participants were more likely to rate their physical health as "Excellent" when compared to houseworkers (34.1\%-17.5\%, respectively). However, when "Excellent" is combined with the category of "Good," the differences disappear. Apparently, the relationship between health, housework, and labor force participation remains unclear.

Poor physical or mental health is likely to interfere with completing household chores or performing duties required by one's job. Conversely, heavy demands of housework or paid labor, compounded by other issues, may negatively influence mental health for women. In light of these considerations, we expect that lower levels of health will be related to reports of greater physical and mental job demands for both the houseworker and those women in the paid labor force. We cannot, with cross-sectional data, truly untangle the direction of these effects, but their associations are important to the model comparing perceptions of work demands.

\section{Time Investment/Hours}

The amount of time invested in paid labor or in housework will influence the level of perceived job demands as well. For houseworkers we hypothesize that the more hours invested in performing household chores, the more physically and mentally taxing the job will be perceived.

For women in the paid labor force the relationship is not so straightforward. Certainly full- and part-time workers invest different numbers of hours. However, women in part-time jobs may attempt to accomplish tasks that are comparable to women in full-time positions, or may be less able to afford the day care and conveniences to lessen their home burdens. Women in full-time jobs carry the burden of the "second shift" of home work and child care in addition to a $40+$ hour week at their paid 
job. In either case, it is important to examine these full-time and part-time workers separately for their perceptions of their paid labor force participation. (In this research, we do not examine their perceptions of their additional household tasks. The data set we use examines perceptions only for the respondent's primary work identity.)

\section{Occupational Sector}

We expect variations across the occupational sectors for women in the paid labor force to influence perceptions as well. As the job more closely approximates the professional level, it may be less physically taxing, yet more mentally demanding. Women, however, are actually underrepresented in these "true" professions as lawyers and physicians (Etzioni, 1969). Instead, women are highly overrepresented in the semiprofessions of nursing, social work, and elementary school teaching (Statham, Miller, \& Mauksch, 1988). Etzioni (1969, p. xiv) characterizes semiprofessionals as having less autonomy, tightly regulated work days, and frequent evaluations made of their work performance. Combined with the physical requirements of caring for patients, visiting clients in the field, and controlling school-aged children, working as a "professional" for many women may be as physically taxing as jobs in other labor market sectors.

\section{Motivational Factors}

Schooler et al. (1984) focus on factors that motivate women workers, contrasting houseworkers and paid labor force participants. They hypothesize that altruism may be a stronger motivation for women in the household than for women in the work place. These different motivations may also affect perceptions of work for women. Feree (1980) found varying levels of satisfaction with work for houseworkers and paid labor force participants were also associated with social class. Working class women drew greater satisfaction from their paid labor (relative to household work), because household work was less satisfying for these women than for middle class women.

Both of these findings lead to explorations about the diverse factors that motivate women to do the work they do, whether in the household or the labor force. In this exploratory vein, we will examine three dimensions of motivational factors that are applicable to both houseworkers and women in the labor force. These three dimensions include (1) the technical demands of paid labor and housework, (2) the expectations of 
"others" in the work setting (employers, co-workers or family members), and (3) the self-expectations of women doing the work.

The first dimension assesses the technical demands of the work women undertake. Is the work perceived as set at a "hard and fast" pace, or is it work that can be done at a leisurely pace and without much difficulty? If women workers, paid or unpaid, perceive their work as demanding a fast pace, and as something that is hard to do, their perceptions of the work may also be affected. We expect that as the urgency and difficulty of women's chores and technical assignments increase, they will report higher levels of mental and physical demands, regardless of the home or labor force status of the work.

The second dimension identifies the amount of pressure women workers feel from others around them. Are women workers, both unpaid and paid, motivated to get their work completed because others around them (employers, co-workers, or family members) depend on them? Does this dependency add to the demand perceptions women have of their workload? We expect that increased pressures from others who are depending on these women workers will increase the perceived physical and mental demands on women workers.

The final dimension is that of self-expectations. Is setting high standards or expectations for oneself a significant motivator in terms of getting a job done? Do perceptions of the workload correspond with what expectations we place on ourselves? Self-expectations may be an important motivator for work, and those expectations may be physical or mental in nature. We suggest that women in the labor force and houseworkers will feel increased mental and physical demands from higher levels of self expectations.

These dimensions are included to address the affective context of work, whether paid or unpaid. They will help identify the range of complex factors that motivate women to work and that affect their perceptions of their jobs.

In this analysis, we examine differences between women working full time in the home and women in the paid labor force, taking into account full-time or part-time employment. We focus on the primary work role (whether paid or unpaid labor). The limits of the data set do not allow us to examine the double shift of work for employed women workers. While this is a serious omission for a complete discussion of women's work lives, for our purposes it is useful to focus first on the major work role women describe for themselves. We will describe their perceptions of the physical and mental demands of their work, and compare factors that intervene to heighten or reduce the perceived demand level. Those factors include respondent education, health status, presence of children, residence setting, and hours committed to the job. We also examine the 
effects of the reported source of motivation for the women workers, ranging from self-motivation, co-worker or family expectations, and the technical demands of the job.

\section{Methods}

The data for this study were collected by the Bureau of Sociological Research at the University of Nebraska-Lincoln as part of the Nebraska Annual Social Indicators Survey, 1983 (NASIS). NASIS is a yearly quality of life survey asking questions on topics from the environment to housing to medical care to education. A total of 1834 usable interviews were obtained by telephone interview from noninstitutional respondents age 18 and older (Moore, 1984).

In this paper, we examine perceptions of the primary work status of women respondents who claim to be working the past week in full or part time wage labor, or as houseworkers. Nine hundred and thirty-nine women participated in the survey. Table I provides their demographic background. Nearly half of the sample (49\%) describe themselves as working full time or part time in the labor force, while 37\% "keep house." The "other" category includes women who are retired, students, unemployed workers, and so forth. The final sample size is 807 .

\section{Dependent Variables}

The dependent variables assess respondents' perceptions of the physical and mental demands of their work. Both groups of women, whether houseworkers or paid labor force participants, were asked the following questions about their respective jobs: "How often does your (job/housework) require you to work very hard physically" and "how often does your (job/housework) require you to work very hard mentally?" Response sets for both of these questions ranged from very often (5), to fairly often, sometimes, rarely, and never (1).

The average response to physical demands for labor force participants was $2.54(S D=.31)$ and for houseworkers, $2.88(S D=1.07)$. These differences are significant $(F=15.383, p<.001)$, with houseworkers reporting their work to be more physically demanding than labor force participants.

For perceptions of mental demands, the mean score for labor force participants was $4.00(S D=1.17)$ and for houseworkers, $2.63(S D=1.16)$. These differences are also significant with paid labor force participants perceiving their work as more mentally demanding than houseworkers $(F=271.3, p \leq .001)$. 
Table I. Independent Variables in the Study

\begin{tabular}{|c|c|c|}
\hline & $\begin{array}{l}\text { Paid labor force } \\
\qquad(N=462)\end{array}$ & $\begin{array}{l}\text { Houseworkers } \\
(N=345)\end{array}$ \\
\hline $\begin{array}{l}\text { \% with preschoolers } \\
\qquad(F=4.45, p=.04)\end{array}$ & 14.7 & 20.6 \\
\hline $\begin{array}{l}\text { \% in residence setting }\left(X^{2}=46.43, p \leq .001\right) \\
\text { Rural farm } \\
\text { Rural nonfarm } \\
\text { City/town } \\
\text { Metropolitan }\end{array}$ & $\begin{array}{l}10.1 \\
11.0 \\
42.7 \\
38.3\end{array}$ & $\begin{array}{r}28.4 \\
8.1 \\
36.5 \\
27.0\end{array}$ \\
\hline $\begin{array}{l}\text { Mean years of education } \\
\qquad(F=25.74, p \leq .001)\end{array}$ & 13.3 & 12.4 \\
\hline $\begin{array}{l}\text { Mean reported health status } \\
\qquad(F=18.30, p \leq .001)\end{array}$ & 2.30 & 2.08 \\
\hline $\begin{array}{l}\text { Mean esteem score } \\
\qquad(F=0.015, p \geq .050)\end{array}$ & 13.51 & 14.17 \\
\hline $\begin{array}{l}\text { Mean health score } \\
\qquad(F=14.14, p \leq .002)\end{array}$ & 4.89 & 4.16 \\
\hline $\begin{array}{l}\text { Mean others depend score } \\
\qquad(F=37.05, p \leq .001)\end{array}$ & 0.70 & 0.49 \\
\hline $\begin{array}{l}\text { Mean require score } \\
\qquad(F=57.51, p \leq .001)\end{array}$ & 0.44 & 0.20 \\
\hline $\begin{array}{l}\text { Full time/part time, hours score } \\
\text { (not directly comparable) }\end{array}$ & $39 \%$ & 3.27 \\
\hline $\begin{array}{l}\text { \% by occupational category } \\
\text { (paid labor force workers only) } \\
\text { Service } \\
\text { Clerical-sales } \\
\text { Semiprofessional } \\
\text { Professional }\end{array}$ & $\begin{array}{l}29 \\
40 \\
15 \\
16\end{array}$ & \\
\hline
\end{tabular}

\section{Independent Variables}

The independent variables (see Table I) provide us with a clearer picture of what factors are associated with women's definitions of their work activity, whether in the labor force or in the home. We assess the following independent variables: presence of preschoolers, educational attainment, rural/urban residence, health status, occupational sector (for paid labor force participants), time investment, and motivation factors. 
The number of preschoolers was dummy coded $(0=$ no preschoolers in the home), with 1 representing one or more preschoolers in the home during the time of the study. Fifteen percent of the paid labor force participants and $21 \%$ of the houseworkers had preschoolers in the home during the time of the study.

Educational attainment was categorized as follows: 0 less than a high school degree, 1 high school degree, 2 one to three years of college, and 4 college degree. The average years of education for labor force participants was 13.3, and for houseworkers, 12.4 years. Four categories represent the residential differences for rural and urban groups of women: 1 rural farm, 2 rural nonfarm, 3 city/town, and 4 metropolitan area. Ten percent of the paid labor force participants and $28 \%$ of the houseworkers lived on a rural farm, while $38 \%$ of the labor force participants and $27 \%$ of the houseworkers lived in a metropolitan area.

The health status of respondents was self-reported as (4) excellent, (3) good, (2) fair, and (1) poor in response to the following question: "Would you say your own health, in general is excellent, good, fair or poor?" The average score reported by labor force participants was significantly higher, 2.30, than for houseworkers, 2.08 ( $F=18.3, p \leq .001)$.

Time investment variables were measured differently for each group of women. The number of hours per week homeworkers spent on housework is broken down as follows: 1-10 (1), 11-20 (2), 21-30 (3), 31-40 (4), 41-50 (5), and 51 hours or more (6). Only $3 \%$ of homeworkers report devoting fewer than 10 hours per week to their chores, and 35\% report a range of 50-100 hours of work per week, for a mean score of 3.27. For labor force participants, time investment was coded as either full-time labor (0), which consisted of 35 or more hours per week in the labor force, or part-time labor (1), which was 1-34 hours per week. One hundred and eighty-three women reported working full-time during the survey, and 209 reported part-time employment. The jobs these women held in the paid labor force (occupation) were categorized as follows: service work (1), clerical/sales (2), semiprofessional (3), and professional/managerial work (4).

Motivational factors were assessed with a set of three indicators, each dummy coded (yes $=1$, no $=0$ ). The following question was asked of both groups of women: "when you work very fast or very hard, would you say this is mainly because ...." For women in the labor force, they responded yes or no to (a) the "company, supervisors or production schedules require a lot of you" ("require"), (b) "other people depend on you" ("others depend"), and (c) "you expect a lot from yourself ("esteem"). For houseworkers, their yes or no responses were to the following questions: (a) "you have to keep up with daily chores" ("require"), (b) "your spouse/family depends a lot on you" ("others depend"), and (c) "you expect a lot from yourself ("esteem"). 
Table II. Correlations with Physical and Mental Demand Perceptions for Labor Force Participants and Houseworkers

\begin{tabular}{|c|c|c|c|c|}
\hline \multirow[b]{2}{*}{ Variables } & \multicolumn{2}{|c|}{ Labor force demands } & \multicolumn{2}{|c|}{ Housework demands } \\
\hline & Physical & Mental & Physical & Mental \\
\hline Preschoolers & $-.068^{a}$ & $-.060^{\mathrm{a}}$ & $.104^{c}$ & $.130^{c}$ \\
\hline Education & $.065^{\mathrm{a}}$ & $.187^{\mathrm{c}}$ & $-.115^{c}$ & $-.120^{c}$ \\
\hline Health status & $.080^{\mathrm{b}}$ & $.130^{c}$ & $-.085^{b}$ & $-.078^{\mathrm{b}}$ \\
\hline Urban residence & $.142^{c}$ & $.224^{\mathrm{c}}$ & $-.176^{c}$ & $-.183^{c}$ \\
\hline Hours spent (full time/part time) & $-.097^{b}$ & $-.207^{c}$ & $.307^{c}$ & $.244^{c}$ \\
\hline Occupation sector & & not applicab & & \\
\hline Service jobs & $.323^{c}$ & $-.312^{c}$ & & \\
\hline Skilled crafts & $-.321^{c}$ & $.092^{\mathrm{a}}$ & & \\
\hline Clerical/sales & .030 & $.119^{\mathrm{a}}$ & & \\
\hline Professional/managerial & .006 & $.130^{\mathrm{b}}$ & & \\
\hline Self-esteem & $.139^{c}$ & $.179^{c}$ & $-.071^{\mathrm{a}}$ & $-.058^{a}$ \\
\hline Others depend & .047 & $.104^{\mathrm{b}}$ & $.126^{\mathrm{b}}$ & .070 \\
\hline Required/tech/chores & .053 & $.211^{\mathrm{c}}$ & $.136^{\mathrm{b}}$ & $.094^{\mathrm{a}}$ \\
\hline
\end{tabular}

\section{Findings}

The demographic variables in Table I indicate that in the mid 1980s in the state of Nebraska, women workers in households and in the paid labor force still exhibited some patterns of difference. Women working full time in the home were significantly more likely to have preschoolers in the household, to live in rural farm settings or outside metropolitan areas, and to be currently married.

In Table II we present the associations between the independent and dependent variables, measured by Pearson's $r$. These correlations demonstrate opposing patterns of association for women in the labor force vis à vis women working in the home. The presence of preschoolers is associated with homeworkers' perceptions of work demands as predicted: preschoolers increase perceptions of both physical and mental demands of house- 
work. For women in the labor force a marginal correlation exists such that those holding jobs that are perceived by respondents as less physically and mentally taxing are more likely to have preschoolers in the home.

Higher education levels and better reported health status among homeworkers are associated with a lowering of reported household demand perceptions, and in contrast, women in the labor force with higher education rates and better health status report more demanding physical and mental dimensions of their work. Rural women report more physical and mental demand perceptions in housework, while urban women in the paid labor force report higher perceived demands in both dependent measures.

For women in the paid labor force, the job sector in which they work and full-time or part-time labor status are associated with the demand perceptions. Only service sector jobs were associated with higher perceptions of physical demands, and skilled craft jobs were associated with lower reported physical demands. The mental demands of labor were positively associated with all job sectors, with the exceptions of service sector jobs, which were associated with reports of less mentally demanding work. For labor force participants and homeworkers, the amount of time devoted to their work raised perceptions of both the physical and mental demands.

The three motivational factors each demonstrate different associations with the demand variables for the two work groups of women. The selfesteem measure of motivation is positively associated with increased reports of physical and mental demands for women in the paid labor force, but is negatively associated for women working in the home (although these latter associations are not as strong). For women in wage earning jobs, higher reported perceptions of mental demands are positively associated with the technical demands of the job and reports that co-workers depend upon them. For women working in the home, the higher perceptions of physical demands are positively associated with greater reported dependency of family members and the need to keep up with chores. This latter factor, the demand of chores, is associated with reports of greater mental demands as well.

These associations suggest quite different patterns for the perception of work demands for women working in the home and in the waged economy. In the next section, we develop a regression model to test the effects of the motivation, work, and respondent background characteristics. The dependent variables of physical and mental work demands are regressed on these independent variables. Multiple regression measures the combined linear effects of the independent variables and allows for an estimation of explained variance in the dependent variable. Analyses were performed separately for houseworkers and paid labor force participants. 
Table III. Predicting Perceptions of Physical and Mental Work Demands for Women In the Paid Labor Force

\begin{tabular}{lccccc}
\hline & \multicolumn{2}{c}{ Physical demands } & & \multicolumn{2}{c}{ Mental demands } \\
\cline { 2 - 3 } \cline { 5 - 6 } Variables & Beta & $(S E)$ & & Beta & $(S E)$ \\
\hline Preschoolers & .004 & .156 & & .018 & .142 \\
Education & -.088 & .077 & & .059 & .070 \\
Health status & -.025 & .056 & & -.014 & .051 \\
Urban residence & -.006 & .000 & & .053 & .001 \\
Hours (full time/part time) & -.067 & .113 & & -.224 & $.103^{c}$ \\
Professional/managerial sector & -.220 & $.167^{c}$ & & .237 & $.152^{c}$ \\
Sales/clerical sector & -.099 & $.218^{c}$ & & .217 & $.197^{c}$ \\
Skilled labor & -.452 & $.140^{c}$ & & .250 & $.127^{c}$ \\
Self esteem & .059 & .001 & & .024 & .001 \\
Others depend & -.262 & $.038^{c}$ & & -.049 & .035 \\
Required/tech & .091 & $.115^{\mathrm{a}}$ & & .170 & $.105^{c}$ \\
\multicolumn{1}{c}{$R^{2}$} & & $.229^{c}$ & & & $.200^{c}$ \\
\hline
\end{tabular}

$a_{p}<.05$.

${ }^{\mathrm{b}} p<.01$.

${ }^{c} p<.001$.

\section{Work Demands in the Labor Force}

For women in wage labor, perceptions of the physical demands of their work were affected primarily by the occupation sector variables and the motivational characteristics of their jobs, once other factors were controlled (see Table III). The equation is significant and explains $23 \%$ of the variation in the perceptions reported by these women workers. Women working in service occupations reported significantly higher perceptions of physical demands of their labor than women employed in each of the other categories. Two of the motivational factors remain significant, even when controlling for background characteristics. These include the technical demands of the job and the extent to which others are dependent upon her to finish their own work. None of the background characteristics of family, health, residence, or child status influence the scores on this variable once other independent variables are controlled in the equation. 
Table IV. Predicting Perceptions of Physical and Mental Work Demands for Women Who Are Houseworkers

\begin{tabular}{lcccccc}
\hline & \multicolumn{2}{c}{ Physical Demands } & & \multicolumn{2}{c}{ Mental Demands } \\
\cline { 2 - 3 } \cline { 5 - 6 } Variables & Beta & $(S E)$ & & Beta & $(S E)$ \\
\hline Preschoolers & -.012 & .137 & & .116 & $.163^{\mathrm{a}}$ \\
Education & -.041 & .077 & & -.055 & .091 \\
Health status & -.018 & .052 & & -.007 & .061 \\
Urban residence & .096 & .038 & & .019 & .045 \\
Hours & .252 & $.039^{\mathrm{c}}$ & & .193 & $.046^{\mathrm{c}}$ \\
Self esteem & .083 & .112 & & .166 & $.131^{\mathrm{b}}$ \\
Others depend & .087 & .138 & & .016 & .164 \\
Required/chores & .089 & .110 & & .030 & .131 \\
\multicolumn{1}{c}{$R^{2}$} & \multicolumn{3}{c}{$.115^{\mathrm{c}}$} & & & \multicolumn{2}{c}{$.102^{\mathrm{c}}$} \\
\hline
\end{tabular}

${ }^{\mathrm{a}} p<.05$.

$\mathrm{b}_{p}<.01$.

$c_{p}<.001$.

The perceived mental demands of the work are influenced again by the occupational sector variables, with each category of workers reporting more mentally demanding work than those in the service sector. In addition, the technical demands of the job continue to have a direct effect, even after controlling for education levels and the job sector of employment. Full-time wage employment also predicts more mentally demanding work, given the negative beta for part-time hours with mental demands. None of the background characteristics of health, education, presence of preschoolers, or urban residence affect the outcome variable. The prediction equation for these mental demand perceptions is significant and explains $20 \%$ of the variance in scores.

The same set of demand variables are examined in Table IV for fulltime homeworkers. In each equation, the number of hours invested in housework is the primary determinant of the respondents' perceptions of the physical and mental demands of housework. Only in the mental demands of housework do other variables contribute to the equation. The self-esteem variable and presence of preschoolers also contribute to higher reported perceptions of mental demands of housework, once all other variables are controlled. Note that each equation, while significant, explains substantially less variance in perceptions for homeworkers than for women in wage labor. 


\section{Discussion of the Findings}

To summarize the contexts of the wage economy and the economy of the home, we find that paid labor force participants and homeworkers perceive their work in very different ways. Homeworkers are significantly more likely to see their work as physically demanding. In general, paid labor force participants were significantly more likely to see their work as mentally demanding. This is not to imply that paid labor force participants view their work as physically untaxing, or that homeworkers view theirs as unchallenging intellectually. Rather, these results reflect our original hypothesis that the context of labor differs from the home to the workplace and across wage sectors.

For this analysis, we separated out market sectors and assumed that variations occur in the extent to which occupations provide opportunities for autonomy and activity. Etzioni (1969) and others (Davies, 1982) have argued that even "professional work" (teaching, nursing, social work, and so forth) for women includes higher rates of supervision, evaluation and lower reward than the occupations held predominately by men. We do not accept a completely homogeneous account of "women's work," but are interested in the potential effects of varying work contexts on perceived mental and physical demands.

Much variation occurs in the perceptions of physical demands among women workers. Women in the home perceive their work as significantly more physically demanding than waged women in general. The only variable contributing significantly to the prediction equation, after all other variables are controlled, is the number of hours of housework. It is interesting to note that the presence of preschoolers is not significant, net of the effect of raising the number of hours devoted to housework.

The preschool variable and housework hours do influence perceived mental demands of housework, as does the self-esteem measure. This combination of variables suggests that the balance of raising children and self-motivation associated with such work, add to increased perceptions of mental demands on homeworkers. The mental demands of housework also appear to be linked to self-expectations in a complex way that does not influence the physical demand factor.

We did find substantial differences among women in the different labor market sectors, also, with women in the service sectors reporting the highest physical demand scores. The self motivator variable is not significant to the perceived physical demand outcomes for wage workers, but increased expectations or dependence of others upon her completing her work tasks is related to greater physical demand perceptions. 
As our findings indicate, waged women workers view their work as mentally more taxing because of the requirements others have placed upon them, technical demands of their work, the nature of part-time work, and the market sector of the jobs they hold.

As a parallel to the number of hours homeworkers invest, we included full-time and part-time work status in the analysis of waged workers. Full- time workers report their work as more mentally demanding. This does not imply that part-time workers do not find their work mentally demanding or stimulating, but when education, residence, and other factors are controlled, full-time workers are more likely to perceive their work as mentally demanding.

All of the market sectors examined as dummy codes in the regression analysis demonstrate higher mental demand scores than the service sector. This clearly links to the findings in the motivation factors as well. Women report that the technical demands of their jobs increase their perceptions of the mental demands of the work.

\section{Discussion}

Labor market theorists suggest parallels between the home labor market and the paid labor market because women work in "feminized" sectors that focus on nurturing and service functions. They argue that these characteristics parallel women's work in the home and women's more general social roles. Our results contradict these notions. Indeed, women's perceptions of waged and nonwaged labor differ greatly from one another.

The differing physical and mental demands reported by women in all the market sectors we examined do not, for the most part, overlap. For a wage worker, neither the amount of time she spends working during the week, the presence of preschoolers, nor her place of residence affects her perceptions of the physical demands of her labor. The lack of effect for presence of preschoolers is puzzling given the demographics of working women with young children in the home. It may be that respondents are separating out their perceptions of their waged work from their "other" work, in the same dichotomies used socially.

Perceptions of the physical demands of waged labor are measured almost solely in the variations across job sectors (service work as contrasted to professional, managerial, sales, and skilled labor). Further, her perceptions are intricately interwoven with the actual job dimensions of autonomy and technology. The "on the job" motivators of technical requirements and the dependence of others on her work schedule influence her perceptions of physical demand levels as well. 
For women in the home, only the number of hours invested in housework influences physical demand perceptions, once other factors are controlled. Given the wide range in hours committed to housework activity by the women in our sample, we can suggest that economic and class differences in the ability to hire out or reduce home chores creates substantial variation in the perceptions of women home workers. In sum, the perceived physical demands of the circumstances in which women work vary significantly across work sectors, whether paid or unpaid.

The mental demands of work are perceived differently as well. Women in the wage economy report significantly higher mental demands of their labor than homeworkers. However, this, too varies across wage market sectors. Service workers report consistently lower mental demands of their labor, when compared to women of similar educational and familial status. Full-time status and high technical requirements of the job also increase the perceived mental demands. The labor market in general restricts autonomy and rewards for women, and provides the fewest opportunities for women in service sector work. Interestingly, the dimensions of work regulated by "others" and service sector work lower women's perceptions of the mental demands of their work in a sector that by definition includes meeting the demands of "others."

The work sector for homeworkers and service workers may be shaped by similar outcomes, especially lower mental demands and higher physical demands of the jobs than women working other wage sectors. However, women in the home may find self-expectations and the presence of children a factor in increasing the mental demands and stimulation of their work day, in ways that service workers cannot affect.

The highly routinized nature of women's work, either in the home or in certain sectors of the labor market, suggest that women's perceptions of their work might converge in some contexts. Our research suggests that such parallels do not exist uniformly, but may be most likely in the physical and mental demand perceptions of homeworkers and service workers. Women are directly affected by the environment in which they work, by the type and the amount of the labor, and the motivational/demand factors associated with it. The different role expectations and job motivation factors indicate that educational and familial factors alone do not distinguish perceptions of work for waged and nonwaged women workers.

We introduce some important caveats to this discussion. The nature of the cross-sectional data restrict us from understanding or fully measuring potential effects of health status, child bearing and rearing, and educational effects as these change during an individual's career in paid or unpaid labor. We cannot untangle the direction of health effects in particular, and our measure may be too broad to identify ways in which health contributes to demand perceptions. The high proportion of nonurban 
women allows us to examine this group more carefully, but we lack clear information on the dimensions of their rural work context. As Rosenfeld (1985) notes, these women rarely report accurately their contributions to farm labor, and without this information, we cannot identify the lack of differences for rural and urban workers, once other factors are controlled in the analyses. We should not, however, leap to the conclusion that rural and urban market sectors are homogeneous.

The most telling omission in our study is the lack of information on housework perceptions for those women employed in wage labor. Clearly, full- and part-time labor contexts will be associated with varying perceptions of demands, as will other family and social factors. Because of restrictions in our data set, we cannot examine this important dimension. What we can accomplish is the description of these demand perceptions in the primary work setting for women.

Women workers' responses to women's work cannot be accounted for by simplistic dichotomous models between waged and nonwaged sectors. Nor can women's perceptions of the value and demand of their labor be placed in homogeneous categories of "productive" or "useful" labor. The complexity of the economy mediates the intricate effects of family and education for all women who work. A social and economic definition of work which has artificially divided "waged" and "nonwaged" labor in the past omitted important dimensions of similarity and difference in women's work perceptions.

\section{References}

Agassi, J. B. (1982). Comparing the work attitudes of women and men. Lexington, MA: Lexington.

Berk, S. F. (1988). Women's unpaid labor: Home and community. In H. Stromberg \& S. Harkess (Eds.). Women working (2nd ed.). Mountain View, CA: Mayfield Publishing.

Berk, S. F. (1985). The gender factory. New York: Plenum Press.

Coleman, L. M., Antonucci, T. C., Adelman, P. K., \& Crohan, S. E. (1987). Social roles in the lives of middle-aged and older black women. Journal of Marriage and The Family, 49, 761-71.

Daniels, A. K. (1987). The hidden work of constructing class and community: Women volunteer leaders in social philanthropy. In N. Gerstel \& H. Gross (Eds.), Families and work. Philadelphia, PA: Temple University.

Davies, M. (1982). Woman's place is at the typewriter. Philadelphia, PA: Temple University Press.

Deckard, B. S. (1983). The women's movement. New York: Harper \& Row.

Devault, M. L. (1987). Doing housework: Feeding and family life. In N. Gerstel \& H. Gross (Eds.), Families and work. Philadelphia, PA: Temple University.

England, P., \& Farkas, G. (1986). Households, employment and gender. New York: Aldine.

Etzioni, A. (1969). The semi-professions and the organization. New York: MacMillan. 
Feree, M. M. (1980). Satisfaction with housework. In S. F. Berk (Ed.), Women and household labor. Beverly Hills, CA: Sage Publications.

Glazer, N. (1987). Servants to capital: Unpaid domestic labor and paid work. In N. Gerstel \& H. Gross (Eds.), Families and work. Philadelphia, PA: Temple University.

Glazer-Malbin, N. \& Waehrer, H. (1976). Woman in a Man-Made World: A Socioeconomic Handbook. Chicago: Rand McNally.

Hartmann, H. I. (1981). The family as the locus of gender, class and political struggle: The example of housework. Signs, 6, 366-94.

Haw, M. A. (1982). Women, work and stress: A review and agenda for the future. Journal of Health and Social Behavior, 23, 132-144.

Haynes, S. G., \& Feinleib, M. (1980). Women, work and coronary heart disease. American Journal of Epidemiology, 111, 37-58.

Juster, F. T., \& Stafford, F. P. (1985). Time, goods and well-being. Ann Arbor, MI: Institute for Social Research.

Kanter, R. M. (1977). Men and women of the corporation. New York: Basic Books.

Liff, S. (1981). Mental health of women factory workers. Journal of Occupational Behavior, 2, 139-146.

Moore, H. A. (1984). Designs, procedures, instruments and forms for the 1983 Nebraska Annual Social Indicators Survey. Lincoln: NB: Bureau of Sociological Research.

Oakley, A. (1980). Reflections on the study of household labor. In S. F. Berk (Ed.), Women and household labor. Beverly Hills, CA: Sage.

Parelius, A. P., \& Parelius, R. J. (1978). The sociology of education. Englewood Cliffs, NJ: Prentice Hall.

Pearlin, L. (1975). Sex roles and depression. In Proceedings of the Fourth Life Span Development Psychology Conference: Normative life crisis. N. Datan \& L. Ginsberg, (Eds.), New York: Academic Press.

Pietromonaco, P. R., Manis, J., \& Frohardt-Lane, K. (1986). Psychological consequences of multiple social roles. Psychology of Women Quarterly, 10, 373-81.

Porter, S. (1978). Your money's worth. Raleigh, NC: Fields Enterprises.

Reskin, B., \& Roos, P. (1990). Job queues, gender queues. Philadelphia, PA: Temple University Press.

Rexroat, C., \& Shehan, C. (1987). The family life cycle and spouse's time in housework. Journal of Marriage and the Family, 49, 737-750.

Robinson, J. P. (1980). Housework technology and household work. In S. F. Berk (Ed.),Women and household labor. Beverly Hills, CA: Sage.

Rosenfeld, R. (1985). Farm women. Chapel Hill: University of North Carolina Press.

Schooler, C., Miller, J., Miller, K., \& Richtand, C. (1984). Work for the household: Its nature and consequences for husbands and wives. American Journal of Sociology, 90, 97-124.

Shehan, C. (1984). Wives work and psychological well-being: An extension of Gove's social role theory of depression. Sex Roles, 11, 881-899.

Shehan, C., Burg, M., \& Rexroat, C. (1986). Depression and the social dimensions of the fulltime housewife role. Sociological Quarterly, 27, 403-421.

Simmons, A., Freedman, A., Dunkle, M., \& Blau, F. (1975). Exploitation from 9-5. Lexington, MA; Lexington Books.

Statham, A., Miller, E., \& Mauksch, H. (1988). The worth of women's work. Albany: State University of New York Press.

Stokes, J. P., \& Peyton, J. S. (1986). Attitudinal differences between full-time homemakers and women who work outside the home. Sex Roles, 15, 299-310.

Wertheimer, B. M. (1977). We were there: The study of working women in America. New York: Pantheon. 